\title{
Evre I larinks kanseri tedavisinde 3 ve 5 Alan Yoğunluk Ayarlı Radyoterapi (3A-YART, 5A-YART) tekniklerinde karotis arterin dozimetrik olarak karşılaştırılması
}

\author{
Ebru CANTÜRK ${ }^{1}$, Gözde TOPGÜL ${ }^{1, *}$, Orhan GÜRLER ${ }^{2}$, Sema TUNÇ $^{3}$, Candan DEMIRÖZ $^{3}$ \\ ABAKAY ${ }^{3}$, Meral KURT ${ }^{3}$, Sibel KAHRAMAN ÇETINTAŞ ${ }^{3}$ \\ ${ }^{1}$ Uludağ Üniversitesi, Sağlık Bilimleri Enstitüsü, Sağlık Fiziği Bölümü, Bursa-TURKEY \\ ${ }^{2}$ Uludağ Üniversitesi, Fen Edebiyat Fakültesi Fizik Bölümü, Bursa-TURKEY \\ ${ }^{3}$ Radyasyon Onkolojisi Anabilim Dall, Tıp Fakültesi, Uludağ Üniversitesi, 16059 Bursa, Turkey \\ Geliș Tarihi (Recived Date): 20.08 .2017 \\ Kabul Tarihi (Accepted Date): 06.12.2017
}

\section{Özet}

Bu çalışmada, radyoterapi (RT) uygulanmış Evre I larinks kanserli 18 hastanın arşiv materyali tedavi planlama sisteminden retrospektif olarak temin edilmiştir. Bu hastalara ait planlama amacıyla çekilmiş bilgisayarl tomografi (BT) verileri kullanılarak MONACO 5.1 tedavi planlama sistemi ile hastaların 3 Alan Yoğunluk Ayarlı Radyoterapi (3A-YART) ve 5 Alan Yoğunluk Ayarlı Radyoterapi (5A-YART) tekniklerinin sanal tedavi planları oluşturulmuştur. Klinik Hedef Hacime (CTV) 63 Gy/fx toplam doz tanımlanmıştır. Tüm tedavi planları CTV' yi kapsayacak şekilde tanımlanan dozun \%95'ine normalize edilmiş ve inhomojenite düzeltmeleri yapılmıştır. Sanal planlar, sağ ve sol karotis arter için doz değerleri doz volüm histogramları (DVH) kullanılarak karşılaştırılmıştır. Elde edilen veriler Sosyal Bilimler için İstatistiksel Paket Programı (SPSS) kullanılarak analiz edilmiştir.

Anahtar kelimeler: Larinks, karotis arter, YART, radyoterapi, doz

\section{Dosimetric comparison of carotid artery with 3 and 5-Field Intensity Modulated Radiotherapy (3F-IMRT, 5F-IMRT) techniques in the treatment of stage I laryngeal cancer}

\begin{abstract}
\footnotetext{
* Gözde TOPGÜL, gozdetopgul@gmail.com, http://orcid.org/0000-0003-4504-3648

Ebru CANTÜRK, ebru_canturk@ hotmail.com , http://orcid.org/0000-0003-2467-8759

Orhan GÜRLER, ogurler@uludag.edu.tr, http://orcid.org/0000-0002-8463-3432

Sema TUNÇ, sgozcu@ gmail.com, http://orcid.org/0000-0003-4697-8234

Candan DEMIRÖZ ABAKAY, candande@uludag.edu.tr, http://orcid.org/0000-0001-5380-5898

Meral KURT, mkurt@uludag.edu.tr, http://orcid.org/0000-0003-1637-910X

Sibel KAHRAMAN ÇETINTAŞ, skahraman@uludag.edu.tr, http://orcid.org/0000-0002-4483-9284
}

In this study, archival material of 18 patients with stage I laryngeal carcinoma treated with radiotherapy (RT) was retrospectively obtained from the treatment planning system. Using the (Computerized Tomography) scans, 3 Field Intensity Modulated Radiotherapy (3F-IMRT) and 5 Field Intensity Modulated Radiotherapy (5F-IMRT) virtual treatment plans were created for the patients with MONACO 5.1 treatment planning system. Prescripted dose for Clinical Target Volume (CTV) is $63 \mathrm{~Gy} / \mathrm{fx}$ in total. All treatment plans were created to conform CTV and normalized to $95 \%$ of the prescripted dose. All inhomogeneity adjustments were made. Virtual plans for dose values for right and left carotid arteries were compared by using Dose- 
Volume Histogram (DVH). The obtained data were analyzed using Statistical Package for Social Sciences (SPSS).

Keywords: Larynx, carotidartery, IMRT, radiotherapy, dose

\section{Giriș}

Larinks; kıkırdaklı içi boş yapıya sahip, bağ, zar ve kaslardan oluşmuş bir organdır.Alt solunum yoluna yakın bir valf (sfinkter) görevi yapar aynı zamanda ses üretimini de sağlar. Boynun ön kısmında 3 ve 6 . servikal vertebralar hizasinda yer alır. Aşağıdakilerden oluşmuş̧ur:

- Üç büyük eşleşmemiş kıkırdak (krikoid, tiroid ve epiglottis)

- Üç çift küçük kıkırdak (aritoit, kronikül ve cuneiform)

- Fibro-elastik membran ve sayısız iç kas.

Klinik evrenin belirlenmesi amaciyla larinks, üç kısma ayrılmıştır. Supraglottik (epiglottis, yalancı vokal kordlar, ventriküller, aryepiglottikfold ve arytenoid), glottik (gerçek vokal kordlar, ön kömmisür) ve subglottik (vokal kordların altı) bölgelerinden oluşur [1].

Larinksin kisımlara ve alt kısımlara (supraglottis, glottis ve subglottis) ayrılmıs olması onkolojik açıdan mantıklı ve faydalıdır. Zira bu ayrım larinks karsinomalarının tanılanmasında ve tedavi planlamasında faydalıdır. Tümör yapılarının gelişimi, hangi anatomik yapının hangi kısmında bulunduğu ile yakından ilişkilidir. Karsinomanın yayılma biçimini de larinks ve anatomik bileșenlerinin özellikleri belirlemektedir. Bu nedenle supraglottis, glottis ve subglottis özelinde bu yapılara has karsinomalara bakmakta yarar bulunmaktadır [2].

Larinks kanseri, cilt dışındaki baş-boyun bölgesi kanserleri arasında en sik rastlanılan kanser çeşididir. Tüm kanser vakaları içindeki oranı ise $\% 2$ civarındadır [3]. Ülkemizde ise erkeklerde en çok görülen ilk on kanser çeşidinden birisidir ve tüm vakaların, \%2,6'sını oluşturmaktadır [4]. Hastalığın tedavi edilmesi için radyoterapi ve cerrahi yaklaşımlar kullanılmakla birlikte bu seçeneklerden birisinin diğerine üstünlüğü konusunda kesin bir kanıya varılmamıştır. Larinks kanseri çoğu vakada tütün ve alkol kullanımı ile ilişkilendirilmektedir, bu nedenle hastaların tedavisi medikal eș morbiditeler ve ikincil primer kanserler ile karmaşıklaşmaktadır [5].

Larinks kanserinde tedavi yaklaşımları geçtiğimiz birkaç on y1lda büyük bir değişim geçirmiştir. Tedavi kararı, genel olarak hastalığın evresine ve tedaviyi uygulayacak kurumun olanaklarına bağlı olarak kararlaştırılmaktadır. Erken evre (I-II) ve İlerlemiş Evre vakalarına tedavi yaklaşımları birbirinden ayrılmıştır [6].

Bütün tedavi yöntemlerinin ana amacı ölüm oranını en aza indirmek ve larinksi koruyabilmektir. Bu yüzden özellikle Evre I Larinks kanserli hastalarda radyoterapi yaklaşımına sıklıkla başvurulmaktadır[7]. Yapılmış çalışmalara göre yalnızca radyoterapi uygulanan hastalarda lokal kontrol oranı \%84 ile \%95 arasında değişmektedir [6].

Bilgisayarlı görüntüleme ile birlikte daha iyi doz dağılımı sağlayabilmek için önce Üç Boyutlu Konformal Radyoterapi Tekniği (3B-KRT), zaman içerisinde daha da karmaşık geometrik yapılarda daha iyi çözümler üretebilmek için Yoğunluk Ayarlı Radyoterapi Tekniği (YART) ve Volümetrik Ark Terapisi Tekniği (VMAT) gibi teknikler geliştirilmiştir [8]. Tedavi planlarını daha iyiye götürmek için yapılan çalışmalar çoğunlukla geleneksel biçimde birden fazla plan oluşturma ve bu planları karşılaştırma biçiminde yürümektedir [9].

Plan kalitesini ve dozimetriyi inceleyip karşılaştıran çalışmalar literatürde bulunmaktadır. Ancak larinksi ve özel olarak erken evre larinks kanserinde farklı tedavi modalitelerini dozimetrik olarak karşılaştıran çalışmalar seyrektir.

Çalışmamızda, Uludağ Üniversitesi Tıp Fakültesi Radyasyon Onkolojisi Kliniği'nde Evre I Larinks Kanseri tanısı ile tedavi edilmiş 18 erkek hasta retrospektif olarak incelenmiş; 3 Alan Yoğunluk Ayarlı Radyoterapi Tekniği (3A-YART) ve 5 Alan Yoğunluk Ayarlı Radyoterapi Tekniği (5A-YART) yöntemleri ve bu iki yöntemde MONACO 5.1 tedavi planlama sistemi kullanılarak yeni tedavi planları oluşturulmuştur.

Her bir hasta için hazırlanan planlar; karotis arterin $\left(\mathrm{V}_{10}, \quad \mathrm{~V}_{30}, \quad \mathrm{~V}_{\text {ort }}\right.$ ve $\left.\mathrm{V}_{\text {mak }}\right)$ parametreleri çeşitli istatistiksel yöntemler kullanılarak karşılaştırılmıştır. Ayrica karotis arteri istenmeyen dozlara en az maruz bırakan teknik; dozimetrik değerlere bakılarak ve uygulanabilirlik (fizibilite) göz önünde bulundurularak saptanmaya çalıșılmıștır. Bütün bu karşılaştırmalardan ortaya çıkacak sonuçların ileride yapılacak optimum plan seçimleri için yararlı bir bilgi sağlaması amaçlanmaktadır. 


\section{Gereç ve yöntemler}

Çalışmamızda temel olarak kullanılan gereçlerden; Siemens Somatom Emotion Duo BT-Simülatör Ünitesi görüntüleme amaciyla, MONACO 5.1. Tedavi Planlama Sistemi planlama amaciyla, SPSS Veri Analiz Programı ise elde edilen tüm verilerin istatistiksel olarak değerlendirilmesi amacıyla kullanılmıştır.

Bilgisayarlı Tomografi (BT) tümörün yapısının tanımlanmasında kullanılmaktadır. BT'nin temel ilkesi, hasta vücudunun istenilen bölgesinden transvers (sagital ya da koronal) yönde geçirilen belirli kalınlıktaki X ışını demetinin doku tarafından soğurulmayan kısmının cihaz detektörlerince tespit edilmesi ve tespit edilen sinyallerin bilgisayar kullanılarak görüntü elde edilmesidir [10].

BT kullanımı, ışınlanacak hedef alanın yüksek doğrulukla belirlenmesine, güvenilirlikle ışınlanmasına ve çevreleyen normal dokuların radyasyon maruziyetini azaltmaya yaramaktadır. Modern BT gereçlerinde simülasyon fonksiyonu da bulunmaktadır. Bu sayede yüksek doğruluk ve hassaslıkta olan tarama verileri, anında tedavi planlama sistemine aktarılabilmektedir [11].

Monaco Tedavi Planlama Sistemi, foton ve elektron temelli bütün tedavi tekniklerinde ve yüksek doğruluk ve kesinlikte işlem yapmayı sağlayan bir yazılımdır. Uludağ Üniversitesi Tıp Fakültesi Radyasyon Onkolojisi Bölümünde bulunan Elekta Synergy Lineer Hizlandırıcı cihazının yazılımıdır. Monte Carlo ve Collapsed Cone (Çökmüş Koni) algoritmalarını standart olarak kabul etmektedir. Kullanımı kolay bir kullanıcı ara yüzü olan sistem; 3B-KRT, YART, VMAT gibi çağdaş tekniklerin planlanmasında kullanılabilmektedir. Plan optimizasyonu sırasında planlara müdahale edebilme olanağı sağlaması, planların istenen biçimde yapılabilmesinde bir avantaj sağlamaktadır. [12].

Farklı tedavi yöntemleri kullanılarak 18 hastanın yeni tedavi planları yapılmıştır ve bu planlardan elde edilen dozimetrik parametrelerin değerleri, IBM SPSS 23 programı vasıtasıyla çeşitli istatistiksel işlemlere tabi tutulmuştur. SPSS 23, istatistiksel özel değerler elde etmekte güvenilir ve kullanımı kolay bir programdır.

$\mathrm{Bu}$ makale çalışmasında Uludağ Üniversitesi Radyasyon Onkolojisi Anabilim Dalı'nda daha önce radyoterapi yapılan 18 Evre I Larinks Kanserli erkek hastaların mevcut olan bilgisayarlı tomografi görüntüleri üzerinde dozimetrik karşılaştırma yapmak için sanal planlar yapıldı. Kullanılan Elekta marka cihazda 18 hastanın planları MONACO 5.1 TPS'de ters planlamada 3A-YART ve 5A-YART olmak üzere 2 farklı teknikle planlama yapıldı.
Planlarda 6 MV'lik enerji kullanıldı ve reçete edilen doz 30 franksiyonda 63 Gy olarak uygulandı. Bu planlarda sağ karotis arter ve sol karotis arter için değerler incelendi. 3A-YART ve 5A-YART planlarının karşılaştırılması amacı ile kullanılan SPSS 23 programı ile hesaplanan değerlerde parametrik olan testlerde T-testi kullanılırken, nonparametrik olanlarda ise Mann-Whitney U testi kullanıldı. Dozimetrik plan değerlendirme metriği aşağıda gösterilmiştir.

- Sol karotid arter ve Sağ karotid arter için V10<\%50 ve V30<\%20

- Sol karotid arter ve Sağ karotid arter için ortalama ve maksimum değeri

\section{Bulgular}

$\mathrm{Bu}$ makale çalışmasında Uludağ Üniversitesi Radyasyon Onkolojisi Anabilim Dalı'nda daha önce radyoterapi yapılan Evre I larinks kanserli 18 erkek hastanın mevcut olan bilgisayarlı tomografi görüntüleri kullanılarak 2 farklı tedavi yöntemi ile sanal planlar yapıldı. Dozimetrik karşılaştırma yapmak için karotis arterin aldığı doz, Doz Volüm Histogramı (DVH) aracılığı ile incelendi.

\subsection{Sol karotiste oluşan dozların bulguları}

Anlamlılık testi sonucu p>0.05 ten büyük çıktığı için sol karotis $\mathrm{V}_{10 \mathrm{~Gy}}$ değişkeni normal dağılıma uygun olduğundan T-testi yapıldı ve bu test sonucu sol karotis $\mathrm{V}_{10 \mathrm{~Gy}}$ doz değeri 2 tekniğin varyansları arasında istatiksel olarak anlamlı fark yoktur $(\mathrm{p}=0.720)$. Analiz sonucunda $\mathrm{p}$ değeri 0.521 bulunduğundan, $\mathrm{p}>0.05$ olduğundan iki teknik arasında sol karotis $\mathrm{V}_{10 \mathrm{~Gy}}$ değişkeni bakımından istatiksel olarak anlamlı fark yoktur. En düşük Ortalama değerine sahip olan tekniğin 3A-YART olduğu görüldü.

Tablo 1. Sol karotiste oluşan değerlerin istatistiksel sonuçları

\begin{tabular}{|c|c|c|c|}
\hline & \multicolumn{2}{|c|}{ 3A-YART } & 5A-YART \\
\hline $\mathbf{V}_{\mathbf{1 0 G y}}(\boldsymbol{\%})$ & Ortalama & $38.26 \pm 3.79$ & $39.05 \pm 3.54$ \\
\hline \multirow{3}{*}{$\mathbf{V}_{\text {30Gy }}(\%)$} & Minimum & 5.12 & 5.32 \\
\cline { 2 - 4 } & Maksimum & 18.71 & 19.68 \\
\cline { 2 - 4 } & Medyan & 14.60 & 15.12 \\
\hline $\mathbf{D}_{\text {ort }}(\mathbf{G y})$ & Ortalama & $11.51 \pm 0.86$ & $11.71 \pm 0.77$ \\
\hline $\mathbf{D}_{\text {mak }}(\mathbf{G y})$ & Ortalama & $52.98 \pm 5.48$ & $51.89 \pm 6.79$ \\
\hline
\end{tabular}

Anlamlılık testi sonucu $\mathrm{p}<0.05$ ten küçük çıktığı için sol karotis $\mathrm{V}_{30 \mathrm{~Gy}}$ değişkeni normal dağılıma uygun olmadığı için Mann-Whitney U testi yapıldı ve bu test sonucu sol karotis $\mathrm{V}_{30 \mathrm{~Gy}}$ doz değeri 2 tekniğin varyansları arasında istatiksel olarak anlamlı fark yoktur ( $p=0.462$ ). En düşük Minimum, Maksimum ve Medyan değeri 3A-YART tekniğinde görüldü. 
Anlamlılık testi sonucu p>0 0.05 ten büyük çıktığı için sol karotis ortalama değeri normal dağılıma uygun olduğundan T-testi testi yapıldı ve bu test sonucu sol karotis ortalama doz değeri 2 tekniğin varyansları arasında istatistiksel olarak anlamlı fark yoktur $(\mathrm{p}=0.706)$. Analiz sonucunda $\mathrm{p}$ değeri 0.469 bulunduğundan, $\mathrm{p}>0.05$ olduğundan iki teknik arasında sol karotis ortalama değerinde istatistiksel olarak anlamlı fark yoktur. En düşük Ortalama değerine sahip olan tekniğin 3A-YART olduğu görüldü.

Anlamlılık testi sonucu p>0 05 ten büyük çıktığ sol karotis maksimum değeri normal dağılıma uygun olduğundan T-testi testi yapıldı ve bu test sonucu sol karotis maksimum doz değeri 2 tekniğin varyansları arasında istatiksel olarak anlaml fark yoktur( $\mathrm{p}=0.278) \cdot \mathrm{p}>0.05$ olduğundan iki teknik arasında sol karotis maksimum değişkeni bakımından istatiksel olarak anlamlı fark yoktur. En düşük Ortalama değerine sahip olan tekniğin 5AYART olduğu görüldü.

\subsection{Să̆ karotiste oluşan dozların bulguları}

Anlamlılık testi sonucu p $>0.05$ ten büyük çıktığı için sağ karotis $\mathrm{V}_{10 \mathrm{~Gy}}$ değişkeni normal dağılıma uygun olduğundan T-testi testi yapıldı ve bu test sonucu sağ karotis $\mathrm{V}_{10 \mathrm{~Gy}}$ doz değeri 2 tekniğin varyansları arasında istatiksel olarak anlamlı fark yoktur $(\mathrm{p}=0.474)$. Analiz sonucunda $\mathrm{p}$ değeri 0.977 bulunduğundan, $\mathrm{p}>0.05$ olduğundan iki teknik arasında sağ karotis $\mathrm{V}_{10 \mathrm{~Gy}}$ değişkeni bakımından istatiksel olarak anlamlı fark yoktur. En düşük Ortalama değerine sahip olan tekniğin 5A-YART olduğu görüldü.

Anlamlılık testi sonucu $\mathrm{p}<0.05$ ten küçük çıktığ sağ karotis $V_{30 G y}$ değişkeni normal dağılıma uygun olmadığ1 için Mann-Whitney U testi yapıldı ve bu test sonucu sağ karotis $\mathrm{V}_{30 \mathrm{~Gy}}$ doz değeri 2 tekniğin varyansları arasında istatiksel olarak anlamlı fark yoktur ( $p=0.462)$. En düşük Minimum, Maksimum ve Medyan değeri sirasiyla 5A-YART, 5A-YART, 3A-YART tekniklerinde görüldü.

Tablo 2. Sağ karotiste oluşan değerlerin istatistiksel sonuçları

\begin{tabular}{|c|c|c|c|}
\hline & & 3A-YART & 5A-YART \\
\hline $\mathrm{V}_{10 \mathrm{~Gy}}(\%)$ & Ortalama & $39.24 \pm 3.51$ & $39.21 \pm 3.25$ \\
\hline \multirow{3}{*}{$V_{\text {30Gy }}(\%)$} & Minimum & 3.55 & 0.23 \\
\hline & Maksimum & 19.55 & 17.89 \\
\hline & Medyan & 14.66 & 15.01 \\
\hline \multirow[t]{3}{*}{$D_{\text {ort }}(G y)$} & Minimum & 9.22 & 8.01 \\
\hline & Maksimum & 12.86 & 13.13 \\
\hline & Medyan & 11.73 & 11.69 \\
\hline$D_{\text {mak }}(\mathbf{G y})$ & Ortalama & $53.17 \pm 6.65$ & $52.13 \pm 8.42$ \\
\hline
\end{tabular}

Anlamlılık testi sonucu $\mathrm{p}<0.05$ ten küçük çıktığı için sağ karotis ortalama değişkeni normal dağılıma uygun olmadığı için Mann-Whitney U testi yapıldı ve bu test sonucu sağ karotis mean doz değeri 2 tekniğin varyansları arasında istatiksel olarak anlamlı fark yoktur ( $\mathrm{p}=0.839)$. En düşük Minimum, Maksimum ve Medyan değeri sirasıyla 5A-YART, 3A-YART, 5A-YART tekniklerinde görüldü.

Anlamlılık testi sonucu p>0.05 ten büyük çıktığı için sağ karotis maksimum değişkeni normal dağılıma uygun olduğundan T-testi testi yapıldı ve bu test sonucu sağ karotis maksimum doz değeri 2 tekniğin varyansları arasında istatiksel olarak anlamlı fark yoktur $(p=0.465)$. Analiz sonucunda $p$ değeri 0.684 bulunduğundan, $\mathrm{p}>0.05$ olduğundan iki teknik arasında sağ karotis maksimum değişkeni bakımından istatiksel olarak anlamlı fark yoktur. En düşük Ortalama değerine sahip olan tekniğin 5AYART olduğu görüldü.

\section{Tartışma ve sonuç}

Son y1llarda gelişen teknolojiye bağlı olarak farklı tedavi uygulama yöntemlerinin ortaya çıkması, doz hesaplama ve planı optimize etmek için gelişmiş yazılımların kullanılmaya başlanması, bu farklı tedavi yöntemleri arasında karşılaştırma yapan araştırmalar yapılmasının önünü açmıştır. Özel olarak evre I larinks kanseri tedavisinde farklı yöntemleri karşılaştıran az çalışma bulunmaktadır [7,13-15].

$\mathrm{Bu}$ nedenle çalışmamızda gelişmiş tedavi tekniklerinden olan YART'ın iki farklı türünü karşılaştırdık. 18 evre I larinks kanserli hastanın BT görüntüleri kullanılarak, 3 Alan Yoğunluk Ayarlı Radyoterapi (3A-YART) ve 5 Alan Yoğunluk Ayarlı Radyoterapi (5A-YART) tekniklerinde tedavi planları oluşturulmuştur.

Sol Karotis $\mathrm{V}_{10 \mathrm{~Gy}}$ değerlerine T-testi uygulanmıştır ve istatistiksel olarak anlamlı bir fark görülmemiştir. Ancak 3A-YART'ın daha düşük ortalama değer ile karotisin daha iyi korunduğu görülmüştür.. Sağ Karotis $\mathrm{V}_{10 \mathrm{~Gy}}$ değerleri incelendiğinde ise en düşük değerler 5A-YART'ta saptanmış ve karotis daha iyi korunmuştur.

Sol Karotis $\mathrm{V}_{\text {30Gy }}$ değerlerinde 3A-YART'1n karotisi daha iyi koruduğu ve düşük değerler gösterdiği saptanmıştır. Sağ Karotis $\mathrm{V}_{30 \mathrm{~Gy}}$ değerlerine bakıldığında en düşük minimum değer 5A-YART'ta karotisin korunduğu görülmüştür.

Sol Karotis $\mathrm{D}_{\text {ort }}$ değerlerine bakıldığında da en düşük ortalama değer ile karotis 3A-YART'ta daha iyi korunduğu, sağ karotis $\mathrm{D}_{\text {ort }}$ değerlerine bakıldığında en düşük minimum değer ile 5A-YART'ta korunduğu görülmüştür. 
Sol Karotis $D_{\max }$ ve sağ karotis $D_{\max }$ değerlerine bakıldığında düşük ortalama değer ile karotisin 5AYART'ta korunduğu görülmüştür.

Gomez ve arkadaşlarının yaptığı ve 3B-KRT ile YART tekniklerini karşılaştırdıkları araştırmada, tanımlanan doz 6300 cGy'di ve 3B-KRT ve YART planları bu doza normalize edilmişti. Bu çalışmada Gomez ve ark., 3B-KRT ve YART teknikleri hedef kapsamı ve normal yapılara (örneğin spinal korda verilen doz bütün tekniklerde tolerans sınırının altında bulunmuştur) klinik açıdan anlamlı doz verilmesi konusunda benzer olduklarını saptamışlardır fakat YART'ın üstün olduğu kısım karotis arterine verilen dozun önemli biçimde azalmış olması ile ortaya çıkmıştır. YART planında karotis arterine verilen ortalama doz konformal terapiye göre neredeyse 2000 cGy daha azdır, bu oldukça önemli bir farka işaret etmektedir. Bu doz değerinin, T1N0 evresinde anterior konumlu bir lezyonu olan hastada, arytenoidi koruyan/sakınan bir plan yapılıp uygulandığında daha da düştüğü görülmüştür [15].

Karotis arterine verilen yüksek dozlu radyasyonun vasküler hastalıklara yol açtığını gösteren yeterli veri bulunmaktadır. Konvansiyonel teknikle tedavi sonrası hastalarda karotis arter stenozu (daralması) ve iskemik felç riskinin arttığını gösteren çalışmalar bulunmaktadır. Dorresteijn ve ark., aralarında larinks karsinoması da olan baş ve boyun kanseri tanısı konulmuş hastalar arasında yaptıkları

\section{Kaynaklar}

[1] Mendelhall, W.M., Mancuso, A.A., ve Amdur, R.J., Perez \& Brady's Principles and Practice of Radiation Oncology, Editörler: Halperin, E.C., Brady, L.W., Perez, C.A. ve Wazer, D.E., Wolters Kluwer 850868 (2013).

[2] Mendelhall, W.M. ve Werning, J.W., Cancer of the Larynx, in Head and Neck Cancer: A Multidisciplinary Approach Editörler: Harrison, R.B., Sessions, L.B., Wolters Kluwer, 441-481 (2013).

[3] Horowitz, D.P., Berman M., Wang, T.J.C. ve Clifford Chao, K.S. Practical Essentials of Intensity Modulated Radiation Therapy, Editör: Clifford Chao, K.S. Wang, T.J.W., Marinetti, T. Philadelphia: Lippincott Williams \& Wilkins 204-236 (2014).

[4] Hacıkamiloğlu, E., Gültekin, M., Boztaş, G., Dündar, S., Şimşek-Utku, E., Kavak-Ergün, A., Sevinç, A., Tütüncü, S. ve Seymen, E. Editörler: Şencan, İ., Keskinkılıç, B., Türkiye Kanser Hastalıkları Raporu, Sağlık Bakanlığı, (2017). incelemede iskemik felç riskinin istatistiksel önem gösterecek biçimde arttığını bulmuşlardır [16]

Matthiesen ve ark., erken evre glottik kanseri tedavisinde YART ve VMAT arasinda bir karşılaştırma yapmışlardır. Bu çalışma VMAT'ın karotis arteri korumasında YART'tan daha iyi olduğunu göstermesidir.Çift Ark VMAT (ÇAVMAT)'ta karotis arterine verilen doz ortalamasının YART'a göre \%6.8 oranında daha az olduğu görüşmüştür $(p<0.001)$ [7].

Riegel ve ark., hem YART'in hem de VMAT'in hedef hacime verilen dozlarda tanımlanan doza uygun sonuçlar verdiğini görmüşlerdir. ÇA-VMAT, Tek Ark-VMAT (TA-VMAT)'a ve YART'a göre daha iyi karotis koruması değerleri sağlamıştır [17].

Evre I larinks kanserlerinin tedavisinde larinksin fonksiyonel olarak korunması lokal kontrolün ve sağkalımın yüksek olmasını sağlayabilmek için çok önemlidir. Aynı zamanda hastaların yaşam kalitesinin korunması için karotis dozlarının dikkate alınarak tedavi planlarının oluşturulması hem larinksin fonksiyon kaybı olasılığını hem de felç riskini azaltabilir. Sonuç olarak, 3 alan ve 5 alan yoğunluk ayarlı radyoterapi teknikleri karotis arteri korumak için tedavide kullanılabilir olduğu görülmüştür. Fakat yan etkiler açısından değerlendirdiğimizde 5 alan yoğunluk ayarlı radyoterapi tekniği uygulama açısından daha iyi olabilir.

[5] Piccirillo, J.F., Importance of Comorbidity in Head and Neck Cancer, The Laryngoscope, 110, 593-602 (2000).

[6] Jenckel F. ve Knecht R., State of the art in the treatment of laryngeal cancer, Anticancer Research, 33, 4701-10. (2013).

[7] Matthiesen, C., Herman, T.de L. ve Singh, H., Dosimetric and radiobiologic comparison of 3D conformal, IMRT, VMAT and proton therapy for the treatment of early-stage glottic cancer, Journal of Medical Imaging and Radiation Oncology, 59, 221-228 (2015).

[8] Hartford, A.C., American Society for Therapeutic Radiology and Oncology (ASTRO) and American College of Radiology (ACR) practice guidelines for Intensity-Modulated Radiation Therapy (IMRT), International Journal of Radiation Oncology-Biology-Physics, 73, 1, 9-14 (2012).

[9] Tol, J.P., Doornaert P., Wittle Bl., Dahele M., Slotman B.J. ve Verbakel, W.F., A longitudinal evaluation of improvements in radiotherapy treatment plan quality for head 
and neck cancer patients, Radiotherapy and Oncology, 11, 2, 337-343, (2016).

[10] Düzgün, F., Boyun kitlelerinde bilgisayarlı tomografi perfüzyon, Celal Bayar Üniversitesi Tip Fakültesi Radyoloji Anabilim Dalı, Tıpta Uzmanlık Tezi, Manisa (2009).

[11] Yildı, S., Elektron Demet Tedavilerinde Doku Heterojenitelerinin ve Yüzey Düzensizliklerinin Doz Dağılımına Etkisi, Yüksek Lisans Tezi, Ankara Üniversitesi Fen Bilimleri Enstitüsü, Ankara (2007).

[12] Monaco Training Guide Version 3.20, IMPAC Medical Systems, Inc. Document ID: LTGMON0320 Part Number: C\#98961-EN (2012).

[13] Camingue, P., Christian, R. ve Ng, D., Comparison of external beam treatment techniques for T1-2, N0, M0 glottic cancers, Medical Dosimetry: Official Journal of The American Association of Medical Dosimetrists, 37, 2, 221-224 (2012).

[14] Atalar, B., Gungor, G., Caglar, H., Aydın, G., Yapıc1, B. ve Ozyar, E., Use of volumetric modulated arc radiotherapy in patients with early stage glottic cancer, Tumori, 98, 331336 (2012).

[15] Gomez, D., Cahlon, O., Mechalakos, J. ve Lee, N., An investigation of intensitymodulated radiation therapy versus conventional two-dimensional and 3Dconformal radiation therapy for early stage larynx cancer, Radiation Oncology, 5, 74 (2010).

[16] Dorresteijn, L.D., Kappelle, A.C., Boogerd, W., Klokman, W.J., Balm, A.J., Keus, R.B., van Leeuwen F.E. ve Bartelink H., Increased risk of ischemic stroke after radiotherapy on the neck in patients younger than 60 years, Journal of Clinical Oncology, 20, 282-288 (2002).

[17] Riegel, A.C., Antone, J. ve Schwartz, D.L., Comparative dosimetry of volumetric modulated arc therapy and limited-angle static intensity modulated radiation therapy for early-stage larynx cancer, Medical Dosimetry, 38, 66-69 (2013). 